\title{
Correlates of group sex participation among men who have sex with men in Chongqing, Southwestern China
}

\author{
Jin Chen ${ }^{1+}$, Hui Fan ${ }^{2 \dagger}$, Huailiang Chen ${ }^{3{ }^{*}+}$ (1) and Feifei Yao ${ }^{4}$
}

\begin{abstract}
Background: Findings from specific countries indicated group sex was common among men who have sex with men (MSM), and men who reported group sex participation were at increased risk of human immunodeficiency virus (HIV)/ sexually transmitted infections (STIs). The purpose of the current analysis was to describe the prevalence and correlates of group sex participation among a community-based sample of MSM in Chongqing, southwestern China.
\end{abstract}

Methods: Convenience sampling method was used to recruit participants and data were collected through an anonymous questionnaire. Logistic regression analysis was employed to identify correlates of group sex participation.

Results: Overall, 1151 eligible participants were enrolled in the study. 14.7\% of MSM reported participating in group sex in their lifetime, and 5.8\% reported group sex participation in the prior 6 months. Factors positively associated with group sex participation in both the prior 6 months and the lifetime included: monthly income $\geq 3000$ Yuan (adjusted odds ratios [aOR] $=3.67$, 95\% confidence interval $[\mathrm{Cl}] 1.25-10.75$; $\mathrm{aOR}=2.30,95 \% \mathrm{Cl} 1.21-$ 4.35), initiating anal sex before 18 years old $(\mathrm{aOR}=1.86,95 \% \mathrm{Cl} 1.03-3.34$; $\mathrm{aOR}=2.00,95 \% \mathrm{Cl} 1.31-3.05)$, using gay apps to seek sex partners ( $\mathrm{aOR}=7.41,95 \% \mathrm{Cl} 2.57-21.33$; $\mathrm{aOR}=9.75,95 \% \mathrm{Cl} 4.92-19.33)$, recreational drug use $(\mathrm{aOR}=10.10,95 \% \mathrm{Cl} 5.52-18.49 ; \mathrm{aOR}=4.75,95 \% \mathrm{Cl} 3.20-7.05)$ and having condomless internal ejaculation (CIE) $(\mathrm{aOR}=3.66,95 \% \mathrm{Cl} 2.01-6.68 ; \mathrm{aOR}=1.61,95 \% \mathrm{Cl} 1.11-2.35)$. Factors only associated with group sex participation in the lifetime were older age (age between 26 and 35 years old: $\mathrm{aOR}=2.06,95 \% \mathrm{Cl} 1.30-3.26$; age > 35 years old: $\mathrm{aOR}=1.95,95 \% \mathrm{Cl} 1.10-3.46)$ and history of STIs ( $\mathrm{aOR}=2.51,95 \% \mathrm{Cl} 1.37-4.62)$.

Conclusions: The results of this study suggested that group sex participation was a potentially risky context for acquisition and transmission of HIV/STIs. Close attention should be given to MSM who participated in group sex, and appropriate risk reduction interventions should be developed specific to this subgroup of MSM.

Keywords: Group sex participation, Correlates, MSM, CIE

\footnotetext{
* Correspondence: chenhuailiang86@163.com

${ }^{+}$Jin Chen, Hui Fan and Huailiang Chen contributed equally to this work.

${ }^{3}$ Department of Infectious Diseases Prevention and Healthcare, the People's Hospital of Sichuan Tianfu New Area, Chengdu, China

Full list of author information is available at the end of the article
}

(C) The Author(s). 2021 Open Access This article is licensed under a Creative Commons Attribution 4.0 International License, which permits use, sharing, adaptation, distribution and reproduction in any medium or format, as long as you give appropriate credit to the original author(s) and the source, provide a link to the Creative Commons licence, and indicate if changes were made. The images or other third party material in this article are included in the article's Creative Commons licence, unless indicated otherwise in a credit line to the material. If material is not included in the article's Creative Commons licence and your intended use is not permitted by statutory regulation or exceeds the permitted use, you will need to obtain permission directly from the copyright holder. To view a copy of this licence, visit http://creativecommons.org/licenses/by/4.0/ The Creative Commons Public Domain Dedication waiver (http://creativecommons.org/publicdomain/zero/1.0/) applies to the data made available in this article, unless otherwise stated in a credit line to the data. 


\section{Background}

A growing body of evidence has indicated that men who have sex with men (MSM) are one of the groups seriously affected by human immunodeficiency virus (HIV) in China. National estimates on the HIV epidemic showed that there were 780,000 people living with HIV (PLHIV) in China by the end of 2011, 17.4\% of which were attributed to homosexual transmission, while sexual contact between men only accounted for 14.7 and $11.0 \%$ of PLHIV in 2009 and 2007, respectively [1, 2]. Additionally, recent update on the HIV epidemic in China revealed homosexual contacts accounted for 25.5\% of new HIV diagnoses in 2017 [3], which was doubled since 2007 (12.2\%) [2].

Findings from Australia, United Kingdom and United States have documented that group sex was a common behavior among MSM [4-7], and men were more likely to report recreational drug use and unprotected anal intercourse (UAI) with casual, HIV unknown or HIV serodiscordant partners in the setting of group sex [7-9]. Thus, men participating in group sex were found at higher risk of infection with and transmission of HIV/sexually transmitted infections (STIs) [9-11]. A small number of reports from coastal metropolises of China have addressed the issue of group sex among MSM [12-14]. However, studies examining factors associated with group sex participation are rather limited in China. Of the existing literature among MSM in China, an online survey from 2014 found men living with HIV, practicing condomless anal intercourse and using mobile phone application were more likely to engage in group sex in 12 the prior months [15]. Another cross-sectional study mainly discussed the correlation between poppers use and lifetime group sex engagement among MSM in the neighboring Sichuan province, southwestern China [16].

Chongqing is the largest provincial municipality located in southwest China. It has a total population of 34.04 million and an area of $82,400 \mathrm{~km}^{2}$ [17]. In the past decades, Chongqing municipality has obtained brilliant achievements in social culture, commerce, economic development and city infrastructure construction [17], which made the city a comprehensive traffic hub and the economic and political center of southwest China. Therefore, a great number of migrant and floating populations nationally were attracted to live and work in this city. Chongqing reportedly has a large population of young MSM. They are sexually active and frequently engaging in sexual risk behaviors [18, 19]. Meanwhile, regular HIV testing level among the subpopulation was low $[19,20]$. Thus, the highest HIV prevalence was observed among MSM in Chongqing [21].

In consideration of the severity of HIV epidemic among MSM in Chongqing and the fact that group sex participation within the subpopulation could potentially fuel the severe epidemic, we sought to describe factors correlated with group sex participation, as well as its relationship with risky behaviors, among a communitybased sample of MSM in this under-researched area. Understanding the factors underlying group sex participation among MSM might inform future interventions for this subpopulation.

\section{Methods}

\section{Study design and participants}

The data used in the current analysis were derived from a larger cross-sectional study aiming to describe recreational drug use, sexual risk behaviors and STIs among MSM in Chongqing. Convenience sampling method was employed to recruit MSM participants through the largest community-based organization (CBO) in Chongqing municipality from March 2019 to February 2020. MSM were requested to join the study when they attended the $\mathrm{CBO}$ for voluntary counseling and testing (VCT) services. Firstly, potential participants were informed of the purpose, procedures, contents and confidentiality issues of the study, and MSM were guaranteed that they could get free VCT services, no matter they participated in the study or not. $\mathrm{CBO}$ staff subsequently checked the eligibility of MSM and asked qualified participants to provide a written informed consent. And then information of participants was collected through a self-administered questionnaire after all these procedures were completed. To obtain necessary sample size, enrolled MSM were encouraged to refer their peers.

Men were eligible for the study if they were at least 18 years old, had sex with males in the prior 12 months and were willing to provide written informed consent. Enrolled participants were paid 25 Yuan $(\sim 4$ American dollar) each as transportation fees. This study was carried out with approval of the ethics committee of the people's hospital of Chongqing Tongliang District and the people's hospital of Sichuan Tianfu New Area.

\section{Data collection}

A self-administered, structured questionnaire was developed to collect information from participants anonymously, and the selected variables for the present analysis could be viewed in Supplementary file 1. In brief, MSM participants were asked to provide their socio-demographics and information on recreational drug use behavior, sexual orientation, main sexual role with males, sexual behaviors, HIV testing and history of STIs.

The main outcome of this study was group sex participation, which was assessed by the questions "Have you ever had sex with three or more men during a single sexual encounter?" and "Have you had sex with three or more men during a single sexual encounter in the prior 6 months?" 


\section{Data analysis}

Frequencies and proportions were used to present categorical variables, and median and interquartile range (IQR) were used to describe continuous variables. Factors correlated with group sex participation were evaluated using logistic regression analysis. Univariate logistic regression analysis was first conducted to examine the odds of factors correlated with group sex participation. Factors significant at $P<0.05$ were subsequently included into the multivariate stepwise logistic regression model to obtain adjusted odds ratios (aORs) and 95\%CI. Significance level was set at $P<0.05$. All analysis was conducted by SPSS 16.0 (SPSS, Inc., Chicago, IL, USA).

\section{Results}

Socio-demographics, drug use and sexual behaviors of participants

Overall, 1151 MSM were included in the present analysis. The demographic characteristics of participants are presented in Table 1 . The median age of enrolled MSM was 28 (IQR 24-34) years old. The majority of participants were unmarried (79.5\%), Chongqing residents (74.4\%) and solo business owners or service providers (66.9\%). Most MSM had at least a college education

Table 1 Sociodemographic characteristics of participants $(n=1151)$

\begin{tabular}{|c|c|c|}
\hline Variables & $\mathbf{n}$ & $\%$ \\
\hline \multicolumn{3}{|l|}{ Age (years) } \\
\hline$\leq 25$ & 410 & 35.6 \\
\hline $26-35$ & 491 & 42.7 \\
\hline$>35$ & 250 & 21.7 \\
\hline Median (IQR) & $28(24-34)$ & \\
\hline \multicolumn{3}{|l|}{ Marital status } \\
\hline Never married & 915 & 79.5 \\
\hline Married & 162 & 14.1 \\
\hline Divorced or widowed & 74 & 6.4 \\
\hline \multicolumn{3}{|l|}{ Residence in Chongqing } \\
\hline Yes & 856 & 74.4 \\
\hline No & 295 & 25.6 \\
\hline \multicolumn{3}{|l|}{ Education } \\
\hline Senior high school and below & 358 & 31.1 \\
\hline College and above & 793 & 68.9 \\
\hline \multicolumn{3}{|l|}{ Occupation } \\
\hline Enterprise, public institution or government & 186 & 16.2 \\
\hline Solo business owners or service providers & 770 & 66.9 \\
\hline Retired, unemployed or students & 195 & 16.9 \\
\hline \multicolumn{3}{|l|}{ Monthly income (Yuan) } \\
\hline$<3000$ & 217 & 18.9 \\
\hline$\geq 3000$ & 934 & 81.1 \\
\hline
\end{tabular}

level (68.9\%) and a monthly income of $\geq 3000$ Yuan (81.1\%).

Of the participants enrolled, 18.9\% (218) reported recreational drug use in the prior 6 months. The most frequently reported drugs were rush poppers (17.7\%), methamphetamine (4.5\%) and magu (1.0\%). Other drugs used among MSM in Chongqing were less than 1.0\% (Table 2).

Table 2 also demonstrates information on sexual behaviors, HIV testing and STIs of MSM participants. Among all participants included, the majority of (66.7\%) MSM self-identified as homosexuality. One-fifths (20.9\%) reported initiating their anal sex before 18 years old. Over two-thirds (67.2\%) reported using cell phone-based applications especially for MSM (gay apps) to seek male sex partners. Almost three-fifths (59.9\%) had more than one sex partner in the prior 6 months, and $41.7 \%$ of MSM reported having condomless internal ejaculation (CIE) during anal intercourse in the prior 6 months. Respectively, $2.7,5.8$ and $14.7 \%$ of MSM reported having participated in group sex in the prior month, in the prior 6 months and in their lifetime. In this sample, less than twofifths (37.2\%) reported having tested HIV recently and $6.3 \%$ reported a history of STIs.

\section{Factors correlated with group sex participation in the prior 6 months}

In the univariate analysis, variables significantly correlated with group sex participation in the prior 6 months $(P<0.05)$ were: monthly income $\geq 3000$ Yuan, initiating anal intercourse before 18 years old, using gay apps to seek sex partners, recreational drug use, practicing CIE during anal intercourse and having a history of STIs (Table 3).

In the multivariate analysis, monthly income $\geq 3000$ Yuan $(\mathrm{aOR}=3.67,95 \%$ CI 1.25-10.75), initiating anal intercourse before 18 years old $(\mathrm{aOR}=1.86,95 \% \mathrm{CI}$ $1.03-3.34)$, using gay apps to seek sex partners $(\mathrm{aOR}=7.41$, 95\% CI 2.57-21.33), recreational drug use $(\mathrm{aOR}=10.10$, 95\% CI 5.52-18.49) and practicing CIE during anal intercourse $(\mathrm{aOR}=3.66,95 \% \mathrm{CI} 2.01-6.68)$ were significantly associated with group sex participation in the prior 6 months $(P<0.05)$ (Table 4$)$.

\section{Factors associated with group sex participation in the lifetime}

Table 3 also shows univariate analysis of factors significantly associated with group sex participation in the lifetime $(P<0.05)$, including: older age, monthly income $\geq 3000$ Yuan, initiating anal intercourse before 18 years old, using gay apps to seek sex partners, recreational drug use, practicing CIE during anal intercourse and having a history of STIs. 
Table 2 Behaviors and health outcomes among MSM $(n=1151)$

\begin{tabular}{|c|c|c|}
\hline Variables & $\mathrm{n}$ & $\%$ \\
\hline \multicolumn{3}{|l|}{ Drug used in the prior 6 months } \\
\hline Any drug use & 218 & 18.9 \\
\hline Rush poppers & 204 & 17.7 \\
\hline Methamphetamine & 52 & 4.5 \\
\hline Magu & 12 & 1 \\
\hline Capsule zero & 3 & 0.3 \\
\hline Ketamine & 3 & 0.3 \\
\hline Other drugs & 5 & 0.4 \\
\hline \multicolumn{3}{|l|}{ Sexual orientation } \\
\hline Homosexual & 768 & 66.7 \\
\hline Bisexual & 320 & 27.8 \\
\hline Uncertain & 63 & 5.5 \\
\hline \multicolumn{3}{|l|}{ Main sexual role with males } \\
\hline Insertive anal intercourse & 383 & 33.3 \\
\hline Receptive anal intercourse & 265 & 23.0 \\
\hline Versatile anal intercourse & 503 & 43.7 \\
\hline \multicolumn{3}{|c|}{ Initiating anal sex before 18 years old } \\
\hline Yes & 241 & 20.9 \\
\hline No & 910 & 79.1 \\
\hline \multicolumn{3}{|c|}{ Using gay apps to seek sex partners } \\
\hline Yes & 774 & 67.2 \\
\hline No & 377 & 32.8 \\
\hline \multicolumn{3}{|l|}{$\begin{array}{l}\text { Number of male sex partners in the } \\
\text { prior } 6 \text { months }\end{array}$} \\
\hline$<2$ & 462 & 40.1 \\
\hline$\geq 2$ & 689 & 59.9 \\
\hline \multicolumn{3}{|c|}{$\begin{array}{l}\text { Condomless internal ejaculation during } \\
\text { anal intercourse in the prior } 6 \text { months }\end{array}$} \\
\hline Yes & 480 & 41.7 \\
\hline No & 671 & 58.3 \\
\hline \multicolumn{3}{|l|}{ Group sex } \\
\hline Group sex in the prior month & 31 & 2.7 \\
\hline Group sex in the prior 6 months & 67 & 5.8 \\
\hline Group sex in the lifetime & 169 & 14.7 \\
\hline Group sex after drug use & 85 & 7.4 \\
\hline \multicolumn{3}{|l|}{ HIV testing in the prior 6 months } \\
\hline Yes & 428 & 37.2 \\
\hline No & 723 & 62.8 \\
\hline \multicolumn{3}{|l|}{ History of STIs } \\
\hline Yes & 72 & 6.3 \\
\hline No & 1079 & 93.7 \\
\hline
\end{tabular}

Factors associated with increased odds of lifetime group sex participation in the multivariate logistic regression model were: older age (age between 26 and
35 years old: aOR $=2.06,95 \%$ CI 1.30-3.26; age $>35$ years old: $\mathrm{aOR}=1.95$, 95\% CI 1.10-3.46), monthly income $\geq 3000$ Yuan $(\mathrm{aOR}=2.30,95 \%$ CI 1.21-4.35), initiating anal intercourse before 18 years old $(\mathrm{aOR}=2.00$, 95\% CI 1.31-3.05), using gay apps to seek sex partners $(\mathrm{aOR}=9.75,95 \%$ CI 4.92-19.33), recreational drug use $(\mathrm{aOR}=4.75$, 95\% CI 3.20-7.05), practicing CIE during anal intercourse $(\mathrm{aOR}=1.61,95 \% \mathrm{CI} 1.11-2.35)$ and having a history of STIs $(\mathrm{aOR}=2.51,95 \%$ CI $1.37-4.62)$ (Table 4).

\section{Discussion}

The current study aimed to describe the prevalence and correlates of group sex participation among a community-based sample of MSM in Chongqing municipality, where the highest HIV prevalence was observed among MSM in the country. Of the 1151 participants included in this study, 14.7 and 5.8\% reported having participated in group sex in the lifetime and in the prior 6 months, respectively. The prevalence was comparable with results from online survey and metropolises elsewhere in China $[15,22,23]$, but significantly lower than reports in countries, like United States and Australia $[6,7,24]$. The disparity may partly reflect differences in culture and attitudes towards non-mainstream sexual activities.

In the multivariate model, demographic characteristic variables, such as age and monthly income, were found to be positively correlated with group sex participation, which was consistent with prior findings [4, 16]. Older MSM might be more active in sexual sensation seeking and adventurous in sexual behaviors than their younger counterparts [25]. Meanwhile, prior research found group sex was associated with substances use [24], and substances use might be quite an expenditure to lowerincome MSM. Hence, it is understandable that men with older age and higher income were more likely to participate in group sex. Additionally, our study found that earlier anal intercourse initiation was significantly associated with group sex participation. Similar to findings in the current study, prior studies indicated that MSM who initiated their sex experience earlier were more likely to practice risky behaviors in their later life $[26,27]$. Therefore, MSM with such characteristics should be a priority for further interventions towards group sex participation.

Corroborating the prior findings $[15,16]$, we found seeking sex partners through gay applications was positively associated with participating in group sex. In recent years, the use of gay applications, such as Blued and Aloha, has been increasingly popular among MSM in China [28-30]. These applications use the global positioning system (GPS) to identify nearby peers, which have rapidly expanded social networking and partnerseeking opportunities among MSM. Thus, men could 
Table 3 Univariate analysis of factors correlated with participation in group sex $(n=1151)$

\begin{tabular}{|c|c|c|c|c|}
\hline \multirow[t]{2}{*}{ Variables } & \multicolumn{2}{|c|}{ Participation in group sex in the prior 6 months } & \multicolumn{2}{|c|}{ Lifetime participation in group sex } \\
\hline & $\mathrm{OR}(95 \% \mathrm{Cl})$ & $P$ value & $\overline{\mathrm{OR}(95 \% \mathrm{Cl})}$ & $P$ value \\
\hline \multicolumn{5}{|l|}{ Age (years) } \\
\hline$\leq 25$ & 1 & & 1 & \\
\hline $26-35$ & $1.38(0.79-2.42)$ & 0.262 & $2.05(1.39-3.01)$ & $<0.001$ \\
\hline$>35$ & $0.93(0.45-1.93)$ & 0.854 & $1.21(0.74-1.98)$ & 0.451 \\
\hline \multicolumn{5}{|l|}{ Residence } \\
\hline Chongqing & 1 & & 1 & \\
\hline Other & $0.93(0.54-1.63)$ & 0.811 & $1.01(0.70-1.47)$ & 0.950 \\
\hline \multicolumn{5}{|l|}{ Marital status } \\
\hline Single & 1 & & 1 & \\
\hline Married or cohabitating & $1.19(0.63-2.27)$ & 0.588 & $1.35(0.88-2.09)$ & 0.171 \\
\hline \multicolumn{5}{|l|}{ Monthly income (Yuan) } \\
\hline$<3000$ & 1 & & & \\
\hline$\geq 3000$ & $3.85(1.39-10.70)$ & 0.010 & $2.89(1.63-5.09)$ & $<0.001$ \\
\hline \multicolumn{5}{|c|}{ Initiating anal sex before 18 years old } \\
\hline No & 1 & & 1 & \\
\hline Yes & $2.63(1.14-6.08)$ & 0.023 & $2.21(1.55-3.15)$ & $<0.001$ \\
\hline \multicolumn{5}{|c|}{ Using gay apps to seek sex partners } \\
\hline No & 1 & & 1 & \\
\hline Yes & $8.26(2.98-22.88)$ & $<0.001$ & $9.49(4.94-18.21)$ & $<0.001$ \\
\hline \multicolumn{5}{|c|}{ Recreational drug use in the prior 6 months } \\
\hline No & 1 & & 1 & \\
\hline Yes & $16.04(9.03-28.48)$ & $<0.001$ & $6.46(4.54-9.19)$ & $<0.001$ \\
\hline \multicolumn{5}{|c|}{$\begin{array}{l}\text { Condomless internal ejaculation during anal } \\
\text { intercourse in the prior } 6 \text { months }\end{array}$} \\
\hline No & 1 & & 1 & \\
\hline Yes & $4.12(2.37-7.18)$ & $<0.001$ & $1.64(1.18-2.27)$ & 0.003 \\
\hline \multicolumn{5}{|c|}{ HIV testing in the prior 6 months } \\
\hline No & 1 & & 1 & \\
\hline Yes & $1.40(0.85-2.30)$ & 0.187 & $0.89(0.63-1.25)$ & 0.508 \\
\hline \multicolumn{5}{|l|}{ History of STIs } \\
\hline No & 1 & & 1 & \\
\hline Yes & $2.52(1.19-5.31)$ & 0.016 & $3.70(2.22-6.17)$ & $<0.001$ \\
\hline
\end{tabular}

$\mathrm{Cl}$ confidence interval, $O R$ odds ratio

effectively arrange or participate in group sex by using these gay applications. Moreover, MSM who reported recreational drug use were more likely to participate in group sex. It has been previously documented that recreational drug use, especially rush poppers and methamphetamine use, was prevalent among MSM who engaged in group sex [7, 24]. Recreational drugs were reported to increase libido, maintain erection, prolong sexual activity and maximize sexual pleasure $[31,32]$. This may explain the reason for higher prevalence of group sex participation among recreational drug users observed in this study.
In accordance with findings from previous studies, we found participating in group sex was associated with increased odds of practicing CIE during anal intercourse. Although it is not possible to determine from this study whether the risk behavior occurred in the context of group sex, existing literature indicated that MSM who attended sex parties practiced higher levels of UAI [7, 8]. Given the severity of HIV/STIs among MSM in Chongqing, the risky combination of group sex participation and CIE during anal intercourse could potentially fuel the epidemics among this subpopulation. Moreover, we found MSM ever 
Table 4 Multivariate analysis of factors correlated with participation in group sex $(n=1151)$

\begin{tabular}{|c|c|c|c|c|}
\hline \multirow[t]{2}{*}{ Variables } & \multicolumn{2}{|c|}{ Participation in group sex in the prior 6 months } & \multicolumn{2}{|c|}{ Lifetime participation in group sex } \\
\hline & $\mathrm{aOR}(95 \% \mathrm{Cl})$ & $P$ value & $\mathrm{aOR}(95 \% \mathrm{Cl})$ & $P$ value \\
\hline \multicolumn{5}{|c|}{ Age (years) } \\
\hline$\leq 25$ & & & 1 & \\
\hline $26-35$ & & & $2.06(1.30-3.26)$ & 0.001 \\
\hline$>35$ & & & $1.95(1.10-3.46)$ & 0.017 \\
\hline \multicolumn{5}{|c|}{ Monthly income (Yuan) } \\
\hline$<3000$ & 1 & & 1 & \\
\hline$\geq 3000$ & $3.67(1.25-10.75)$ & 0.018 & $2.30(1.21-4.35)$ & 0.011 \\
\hline \multicolumn{5}{|c|}{ Initiating anal sex before 18 years old } \\
\hline No & 1 & & 1 & \\
\hline Yes & $1.86(1.03-3.34)$ & 0.039 & $2.00(1.31-3.05)$ & 0.001 \\
\hline \multicolumn{5}{|c|}{ Using gay apps to seek sex partners } \\
\hline No & 1 & & 1 & \\
\hline Yes & $7.41(2.57-21.33)$ & $<0.001$ & $9.75(4.92-19.33)$ & $<0.001$ \\
\hline \multicolumn{5}{|c|}{ Recreational drug use } \\
\hline No & 1 & & 1 & \\
\hline Yes & $10.10(5.52-18.49)$ & $<0.001$ & $4.75(3.20-7.05)$ & $<0.001$ \\
\hline \multicolumn{5}{|c|}{$\begin{array}{l}\text { Condomless internal ejaculation during } \\
\text { anal intercourse in the prior } 6 \text { months }\end{array}$} \\
\hline No & 1 & & 1 & \\
\hline Yes & $3.66(2.01-6.68)$ & $<0.001$ & $1.61(1.11-2.35)$ & 0.013 \\
\hline \multicolumn{5}{|c|}{ History of STIs } \\
\hline No & 1 & & 1 & \\
\hline Yes & $1.16(0.49-2.77)$ & 0.735 & $2.51(1.37-4.62)$ & 0.003 \\
\hline
\end{tabular}

$\mathrm{Cl}$ confidence interval, aOR adjusted odds ratio

participating in group sex were more likely to report history of STIs. The relationship between group sex participation and STIs was discussed in previous studies [33-35]. A high partner turnover rate and low condom use rate in the context of group sex might contribute to infection with and transmission of STIs among men participating in group sex. Therefore, our findings highlight the need for interventions on group sex participation and associated risky behaviors.

This study has a few limitations. Firstly, our study may be vulnerable to selection bias, as all participants in this study were recruited by a CBO. Secondly, data on recreational drug use, sexual behaviors and history of STIs were still sensitive in China, and the results might be subjected to social desirability bias. Thirdly, our findings were based on a self-administered questionnaire and recall bias might exist. Lastly, due to the nature of crosssectional study, we can not infer causal relationships between group sex participation and associated factors. Future research in China should be conducted to collect an event-level behavioral data related to group sex, which may contribute to better understanding of the risks posed by group sex participation.

\section{Conclusions}

Although the prevalence of group sex participation among MSM in Chongqing was not comparable with results from western countries, still we found MSM participating in group sex were more likely to report recreational drug use and CIE during anal intercourse. Thus, group sex might be a risky setting, posing an elevated risk for HIV infection and other STIs. More attention should be paid to group sex among MSM, and appropriate risk reduction interventions should be developed specific to this subgroup of MSM.

\section{Abbreviations}

MSM: Men who have sex with men; HIV: Human immunodeficiency virus; STIs: Sexually transmitted infections; aOR: adjusted Odds ratio; OR: Odds ratio; $\mathrm{Cl}$ : Confidence interval; CIE: Condomless internal ejaculation; PLHIV: People living with HIV; UAI: Unprotected anal intercourse; CBOs: Community-based organizations; VCT: Voluntary counseling and testing; IQR: Interquartile range; CDCs: Centers for disease control and prevention; GPS: Global positioning system 


\section{Supplementary Information}

The online version contains supplementary material available at https://doi. org/10.1186/s12889-021-10607-0.

Additional file 1. Questionnaire for MSM in Chongqing. Questionnaire for MSM in Chongqing.

\section{Acknowledgements}

We are grateful to the staff members from Chongqing Jiangbei CDC for their support in the questionnaire design. We also wish to thank all the staff from Chongqing Bluesky health care work group for their efforts in participant recruitment and questionnaire survey.

\section{Authors' contributions}

$\mathrm{CHL}$ and $\mathrm{CJ}$ conceived and designed the study. CJ, FH and CHL performed the data analyses and drafted the manuscript. FH and YFF helped to critically review the manuscript. All authors have read and approved the final manuscript.

\section{Funding}

This project was funded by joint project of Chongqing Science and Technology Commission and Chongqing Health and Family Planning Commission (2018QNXM044) and Science and Technology Commission of Tongliang District, Chongqing (2018-20). The grant funders had no role in the study design, data collection, analysis and interpretation, or preparation of the manuscript.

\section{Availability of data and materials}

The datasets used during the current study are available from the corresponding author on reasonable request.

\section{Declarations}

\section{Ethics approval and consent to participate}

The protocol of this study was reviewed and approved by the Ethics Committee of the people's hospital of Chongqing Tongliang District and the people's hospital of Sichuan Tianfu New Area. Written informed consent was obtained from all participants.

\section{Consent for publication}

Not applicable.

\section{Competing interests}

All authors declare that they have no competing interests.

\section{Author details}

'Department of Medical Records and Statistics, the People's Hospital of Tongliang District, Chongqing, China. ${ }^{2}$ Department of Preventive Medicine, North Sichuan Medical College, Nanchong, China. ${ }^{3}$ Department of Infectious Diseases Prevention and Healthcare, the People's Hospital of Sichuan Tianfu New Area, Chengdu, China. ${ }^{4}$ Department of STD/HIV Control and Prevention, Sichuan Tianfu New Area Center for Disease Control and Prevention, Chengdu, China.

Received: 10 August 2020 Accepted: 10 March 2021 Published online: 22 March 2021

\section{References}

1. China Ministry of Health, Joint United Nations Programme on HIV/AIDS and World Health Organization. 2011 Estimates for the HIV/AIDS epidemic in China. Beijing: China Ministry of Health, 2011. Available online at: http://nca ids.chinacdc.cn/jb/fzdt/zxdd/201201/t20120129_1745902.htm. [verified 6 August 2020].

2. China State Council AIDS Working Committee Office and UN theme Group on HIV/AIDS in China. Joint Assessment of HIV/AIDS Prevention and Treatment in China (2007). Beijing: China Ministry of Health, 2007. Available online at: http://www.chinaaids.cn/ddpg//hpgbg1/zgazbyq/201312/W02 0131220518731205501.pdf. [verified 6 August 2020].
3. National Center for AIDS/STD Control and Prevention, China CDC. Update on the AIDS/STD epidemic in China in December 2017. Chin J AIDS STD. 2018;24(2):111.

4. Prestage G, Down I, Grulich A, Zablotska I. Sex partying among gay men in Sydney, Melbourne and Brisbane, Australia. AIDS Behav. 2011;15(2):298-304. https://doi.org/10.1007/s10461-010-9824-7.

5. Goedel WC, Duncan DT. Correlates of engagement in group sex events among men who have sex with men in London who use geosocialnetworking smartphone applications. Int J STD AIDS. 2018;29(3):244-50. https://doi.org/10.1177/0956462417722478.

6. Phillips $G$, Magnus M, Kuo I, et al. Correlates of group sex among a community-based sample of men who have sex with men (MSM) in Washington, DC. AIDS Behav. 2014;18:1413-9.

7. Mimiaga MJ, Reisner SL, Bland SE, Driscoll MA, Cranston K, Isenberg D, VanDerwarker R, Mayer KH. Sex parties among urban MSM: an emerging culture and HIV risk environment. AIDS Behav. 2011;15(2):305-18. https://doi org/10.1007/s10461-010-9809-6.

8. Prestage GP, Hudson J, Jin F, Corrigan N, Martin P, Grulich AE, Mclnnes D. Testing for HIV and sexually transmissible infections within a mainly online sample of gay men who engage in group sex. Sex Transm Infect. 2009; 85(1):70-4. https://doi.org/10.1136/sti.2008.031120.

9. Prestage GP, Hudson J, Down I, Bradley J, Corrigan N, Hurley M, Grulich AE, Mclnnes D. Gay men who engage in group sex are at increased risk of HIV infection and onward transmission. AIDS Behav. 2009;13(4):724-30. https:// doi.org/10.1007/s10461-008-9460-7.

10. Grov C, Rendina HJ, Ventuneac A, Parsons JT. HIV risk in group sexual encounters: an event-level analysis from a national online survey of MSM in the U.S. J Sex Med. 2013;10(9):2285-94. https://doi.org/10.1111/jsm.12227.

11. Friedman SR, Bolyard M, Khan M, Maslow C, Sandoval M, Mateu-Gelabert P, Krauss B, Aral SO. Group sex events and HIV/STI risk in an urban network. J Acquir Immune Defic Syndr. 2008;49(4):440-6. https://doi.org/10.1097/QAI. Ob013e3181893f31.

12. Chen X, Li X, Zheng J, Zhao J, He J, Zhang G, Tang X. Club drugs and HIV/ STD infection: an exploratory analysis among men who have sex with men in Changsha, China. PLoS One. 2015;10(5):e0126320. https://doi.org/10.1371/ journal.pone.0126320.

13. Chu ZX, Xu JJ, Zhang YH, Zhang J, Hu QH, Yun K, Wang HY, Jiang YJ, Geng WQ, Shang H. Poppers use and sexual partner concurrency increase the HIV incidence of MSM: a 24-month prospective cohort survey in Shenyang, China. Scientific Reports. 2018;8(1):24. https://doi.org/10.1038/s41598-017-18127-x.

14. Lin HJ, Zhang YC, Shen WW, Wu QH, Xu YY, Qiu DH, Ding YY, He N Investigation of group sex in men who have sex with men in Taizhou, Zhejiang province, 2013-2015. Chin J Epidemiol. 2017;38(5):634-7. https:// doi.org/10.3760/cma.j.jssn.0254-6450.2017.05.015

15. Tang WM, Tang SY, Qin YL, Zhang Y, Zhang W, Liu C, Tso LS, Wei C, Yang L, Huang $S$, Yang B, Tucker J. Will gay sex-seeking Mobile phone applications facilitate group sex? A cross-sectional online survey among men who have sex with men in China. PLoS One. 2016;11(11):e0167238. https://doi.org/10.1371/journal.pone.0167238.

16. Chen $\mathrm{HL}$, Yang $\mathrm{Y}$, Huang $\mathrm{YL}$, Dai Y, Zhang J. Prevalence of poppers use and its sexual risks among men who have sex with men in southwestern China: a cross-sectional study. BMC Public Health. 2018;18(1):1103. https://doi.org/1 0.1186/s12889-018-6010-8

17. Chongqing Municipal Bureau of Statistics, National Bureau of Statistics Survey Office in Chongqing. Chongqing Statistical Yearbook 2019. Chongqing: China Statistics Press; 2019.

18. Zhang YC, Wu GH, Lu RR, Xia W, Hu L, Xiong Y, Xie J, Yu Q, Ye M. What has changed HIV and syphilis infection among men who have sex with men (MSM) in Southwest China: a comparison of prevalence and behavioural characteristics (2013-2017). BMC Public Health. 2019;19(1):1314. https://doi. org/10.1186/s12889-019-7730-0

19. Chen J, Huang YL, Chen HL, Xia J. Nitrite inhalants use, sexual behaviors and HIV/ syphilis infection among men who have sex with men in Chongqing, China. Infect Dis Poverty. 2020;9(1):127. https://doi.org/10.1186/s40249-020-00748-6.

20. Li XF, Wu GH, Lu RR, et al. HIV-testing behavior and associated factors among MSM in Chongqing, China. Medicine. 2014;93(27):1-9.

21. Dong MJ, Peng B, Liu ZF, Ye QN, Liu H, Lu XL, Zhang B, Chen JJ. The prevalence of HIV among MSM in China: a large-scale systematic analysis. BMC Infect Dis. 2019:19(1):1000, https://doi.org/10.1186/s12879-019-4559-1.

22. Huang HM, Wang T, Cao Y, et al. Relationship between sexual sensation seeking and risk sexual behaviors among young men who have sex with men. Chin Epidemiol. 2015;36(8):821-4. 
23. Wang XF, Li YQ, Wu ZY, Tang Z, Reilly KH, Nong Q. Nitrite inhalant use and HIV infection among Chinese men who have sex with men in 2 large cities in China. J Addict Med. 2017;11(6):468-74. https://doi.org/10.1097/ADM. 0000000000000347.

24. Prestage G, Grierson J, Bradley J, Hurley M, Hudson J. The role of drugs during group sex among gay men in Australia. Sex Health. 2009;6(4):310-7. https://doi.org/10.1071/SH09014.

25. Prestage G, Kippax S, Jin FY. Does age affect sexual behaviour among gay men in Sydney, Melbourne and Brisbane, Australia? AIDS Care. 2008;21(9): 1098-105.

26. Mmbaga EJ, Leyna GH, Leshabari MT, Moen K. Early anal sex experience among men who have sex with men in Dar Es Salaam Tanzania: implications for HIV prevention and care. Arch Sex Behav. 2020;49(6):204555. https://doi.org/10.1007/s10508-019-01529-5.

27. Xu WJ, Zheng LJ, Song JJ, Zhang X, Zhang X, Zheng Y. Relationship between childhood sexual abuse and HIV-related risks among men who have sex with men: findings from mainland China. Arch Sex Behav. 2018; 47(7):1949-57. https://doi.org/10.1007/s10508-017-1104-4.

28. Wei L, Chen L, Zhang HB, Yang Z, Zou H, Yuan T, Xiao Y, Liu S, Tan W, Xie W, Liu L, Cheng J, Zhao J. Use of gay app and the associated HIV/syphilis risk among non-commercial men who have sex with men in Shenzhen, China: a serial cross-sectional study. Sex Transm Infect. 2019;95(7):496-504. https://doi.org/10.1136/sextrans-2018-053902.

29. Zheng ZW, Yang QL, Liu ZQ, Qiu JL, Gu J, Hao YT, Song C, Jia ZW, Hao C. Associations between affective states and sexual and health status among men who have sex with men in China: exploratory study using social media data. J Med Internet Res. 2020;22(1):e13201. https://doi.org/10.2196/13201.

30. Wang HD, Zhang L, Zhou Y, Wang K, Zhang $X$, Wu J, Wang G. The use of geosocial networking smartphone applications and the risk of sexually transmitted infections among men who have sex with men: a systematic review and meta-analysis. BMC Public Health. 2018;18(1):1178. https://doi. org/10.1186/s12889-018-6092-3.

31. Vaccher SJ, Hammoud MA, Bourne A, Lea T, Haire BG, Holt M, Saxton P, Mackie B, Badge J, Jin F, Maher L, Prestage G. Prevalence, frequency, and motivations for alkyl nitrite use among gay, bisexual and other men who have sex with men in Australia. Int J Drug Policy. 2020;76:102659. https:// doi.org/10.1016/j.drugpo.2019.102659.

32. Prestage G, Jin F, Kippax S, Zablotska I, Imrie J, Grulich A. Use of illicit drugs and erectile dysfunction medications and subsequent HIV infection among gay men in Sydney, Australia. J Sex Med. 2009;6(8):2311-20. https://doi. org/10.1111/j.1743-6109.2009.01323.x.

33. van den Boom W, Davidovich U, Heuker J, Lambers F, Prins M, Sandfort T, Stolte IG. Is group sex a higher-risk setting for HIV and other sexually transmitted infections compared with dyadic sex among men who have sex with men? Sex Transm Dis. 2016;43(2):99-104. https://doi.org/10.1097/ OLQ.0000000000000389.

34. Scheidell JD, Friedman SR, Golin C, Wohl DA, Khan MR. Group sex event participation: a link to STI risk among African-American heterosexual men incarcerated in North Carolina. Sex Transm Infect. 2017;93(2):144. https://doi. org/10.1136/sextrans-2016-052980.

35. Rice CE, Lynch CD, Norris AH, Davis JA, Fields KS, Ervin M, Turner AN. Group sex and prevalent sexually transmitted infections among men who have sex with men. Arch Sex Behav. 2016;45(6):1411-9. https://doi.org/10.1007/s1 0508-015-0554-9.

\section{Publisher's Note}

Springer Nature remains neutral with regard to jurisdictional claims in published maps and institutional affiliations.

Ready to submit your research? Choose BMC and benefit from:
- fast, convenient online submission
- thorough peer review by experienced researchers in your field
- rapid publication on acceptance
- support for research data, including large and complex data types
- gold Open Access which fosters wider collaboration and increased citations
- maximum visibility for your research: over 100M website views per year
At BMC, research is always in progress.
Learn more biomedcentral.com/submissions

